\title{
Precario suburbanismo. Familias de clase media en urbanizaciones de baja densidad en Cataluña ${ }^{1}$
}

\author{
Mikel Aramburu²
}

Recibido: 24 de enero de 2017 / Aceptado: 15 de marzo de 2017

Resumen: En Cataluña, la expansión del urbanismo disperso, conjuntos de casas unifamiliares con jardín separados de los centros urbanos, el equivalente morfológico al suburbio anglosajón, se produjo a partir de los años 70 al margen del planeamiento urbano. En aquel momento estas urbanizaciones albergaban mayoritariamente segundas residencias autoconstruidas por familias de clase obrera, pero a partir de los años 90 se fueron convirtiendo en vivienda habitual de familias de clase media, las cuales han heredado gran parte de la precariedad urbanística constitutiva de estas zonas. A pesar de su peculiar precariedad, el suburbanismo catalán ha sido un territorio muy poco transitado por las ciencias sociales, especialmente desde una perspectiva socio-antropológica. A través de un estudio de caso etnográfico, este artículo analiza el proceso de suburbanización de familias que se han trasladado recientemente a una de estas zonas, al tiempo que discute críticamente aspectos como la homogeneidad social y las tendencias antiurbanas que suelen atribuirse en la literatura a este tipo de configuraciones residenciales. Palabras clave: urbanización dispersa; precariedad urbanística; antiurbanismo; homogeneidad social; clase media.

\section{[en] Precarious suburbanism. Middle Class families in suburban Catalonia}

\begin{abstract}
In Catalonia, urban sprawl and the creation of residential areas of single-family houses separated from the inner city, the morphologically equivalent of the Anglo-Saxon suburb, has remained largely unexplored by the social sciences, especially from a socio-anthropological perspective. From an irregular constituted area of second residences for the working-class, these areas have evolved since de 1990s to a first home sector for middle class families. However, these families have inherited much of the original urban precariousness of these developments. In this article, I explore the suburbanization process through a ethnographic case study, focusing on the perspectives of middle-class families that have moved to one of these areas. Catalan suburbanism is analyzed taking in consideration some interpretative issues of the sociological theory of suburbanism, particularly regarding the social homogeneity and the anti-urban trends that are commonly attributed to these residential sectors.
\end{abstract}

Keywords: Suburbanism; urban 'precariousness; anti-urban trends; social homogeneity; middle-class.

Sumario: 1. Introducción. 2. Estudio de caso: las urbanizaciones de Argentona. 3. Trabajo de campo. 4. ¿Huir de la Ciudad? Factores de atracción. 5. La casa con jardín como proyecto familiar. 6. Los

1 Este artículo se basa en la investigación "Segregación y consumo residencial en la Región Metropolitana de Barcelona" financiado por la Generalitat de Cataluña, en la que colaboraron Jenifer Romero, Alejandro García, Joana Soto y Jaime Palomera. Agradezco a Raúl Márquez e Irene Sabaté, así como a los revisores anónimos de la Revista de Antropología Social, los comentarios realizados a una versión preliminar del artículo.

2 Profesor Titular de Antropología Social en la Universidad de Barcelona.

mikel.aramburu@ub.edu 
trabajos y los días. 7. ¿Espacio de homogeneidad social? 8. Relaciones débiles, control y previsibilidad. 9. Formas de agregación y disgregación en las urbanizaciones. 10. Conclusiones. 11. Referencias bibliográficas

Cómo citar: Aramburu, M. (2017). Precario suburbanismo. Familias de clase media en urbanizaciones de baja densidad en Cataluña, en Revista de Antropología Social 26(1), 31-51.

\section{Introducción}

A partir de finales del siglo XIX, a medida que la ciudad industrial crecía debido a los flujos migratorios, fue surgiendo un movimiento contrario de sectores urbanos que se instalaban fuera la ciudad, en nuevos desarrollos urbanísticos de pequeña escala y baja densidad. Este proceso, llamado de suburbanización, periurbanización o dispersión urbana, según los países, se aceleró después de la Segunda Guerra Mundial hasta convertirse en el tipo de hábitat residencial mayoritario en varios países occidentales $^{3}$. En España, y en concreto en Cataluña, la presencia de este fenómeno es cuantitativamente menor. Se estima que en Cataluña existen en torno a 2.000 "urbanizaciones de baja densidad" (Síndic de greuges, 2013), esto es, conjuntos de chalés separados de los núcleos urbanos densos. En estas urbanizaciones catalanas hay aproximadamente 200.000 viviendas construidas, donde se estima que viven entre 200 y 300 mil personas de forma habitual.

Una de las peculiaridades del suburbio catalán es su elevado grado de precariedad urbanística. Son urbanizaciones creadas casi en su totalidad de manera ilegal a finales del franquismo por parte de empresas promotoras que adquirían terrenos rústicos a bajo precio, los urbanizaban mínimamente (encargándose apenas del pavimento de la calle y del tendido eléctrico, pero a veces ni eso) y vendían las parcelas sin edificar obteniendo con ello altas plusvalías. Estos elementos de irregularidad presentan semejanzas notables con la construcción informal de las periferias urbanas latinoamericanas (Holston 1991, Caldeira 2000, Márquez 2015), siendo la principal diferencia que en un caso comenzaron albergando segundas residencias y en el otro se trataba de viviendas de uso habitual, diferencia que no obstante se irá desdibujando con el tiempo.

Los primeros ayuntamientos democráticos acabaron legalizando estas urbanizaciones, reconociéndolas en el planeamiento como hechos consumados. Pero actualmente sólo el 50\% de estas urbanizaciones están "recepcionadas", es decir, sólo en la mitad de los casos los ayuntamientos asumen los gastos de mantenimiento de los servicios urbanos (conservación de pavimento e iluminación pública, recogida de

\footnotetext{
Ante la ausencia en lengua española de un término que designe de manera inequívoca este fenómeno, utilizaré el término "suburbanización" y no "periurbanización" (de origen francés) porque, a pesar de que el primero tiene en español una connotación de periferia obrera o incluso 'marginal', es un término que está más en línea con la teoría sobre el tema, mayormente anglosajona. En cualquier caso, no resulta sencillo acotar conceptualmente el significado del "suburbio", sobretodo porque no es una realidad estática, ya que en las últimas décadas ha ido experimentando una serie de transformaciones. Si durante las décadas posteriores a la Segunda Guerra Mundial, los residentes suburbanos trabajaban normalmente en el centro urbano obligándose con ello a viajes diarios de casa al trabajo, el nuevo suburbio se va "urbanizando", dejando de ser tan inequívocamente monofuncional. El nuevo suburbio es una exopolis o edge citiy (Davis, 2006), en la que no solo la residencia, sino también los empleos se expanden a la periferia creando núcleos relativamente independientes siguiendo un urbanismo polinuclear.
} 
basuras, etc.). Según las estimaciones de Barba y Mercadé (2007) para la provincia de Barcelona, una cuarta parte de estas urbanizaciones todavía no está pavimentada ni tiene alumbrado público, y más de la mitad no está conectada a la red de alcantarillado. Casi todas carecen de equipamientos comerciales, escolares, sanitarios o culturales. Muchas veces, ni los vecinos pueden costearse los gastos que comporta completar la urbanización ni los ayuntamientos pueden asumir el coste de los servicios, mucho más alto que en la ciudad compacta, generando un problema de política urbana de muy difícil resolución.

Cuando se crearon las urbanizaciones, en los años 60 y 70, los particulares compraban parcelas para construir casas de segunda residencia. Pero a partir de los años 90 , muchas de estas viviendas se fueron convirtiendo en residencia habitual. En este proceso ha influido en primer lugar el incremento exponencial de los precios de la vivienda en los núcleos urbanos, que ha tenido un efecto expulsor sobre muchas familias urbanas, pero también la mejora de la accesibilidad a estas áreas rurales debido a la ampliación de la red de autopistas y autovías, así como la descentralización de actividades económicas, como polígonos industriales y centros logísticos y comerciales.

Dados los numerosos problemas que estas urbanizaciones plantean desde el punto de vista de la gestión urbana, los estudios sobre este tipo de hábitat disperso se han centrado, como evidencian las obras colectivas de Indovina (2007), Muñoz (2011) o Muxí (2013), en una serie de aspectos característicos: la gestión urbanística para dotar a la urbanización dispersa de más complejidad de funciones urbanas; los retos económicos que plantea la expansión territorial de la vivienda unifamiliar desde el punto de vista del mantenimiento de servicios e infraestructuras; los costes ambientales en lo que respecta al consumo de suelo, agua y energía que multiplican los de la ciudad compacta, etc. Pero prácticamente no se han realizado estudios sobre la vida social en las urbanizaciones de baja densidad en Cataluña y España. Igualmente, Lupi y Musterd (2006) señalan que en Europa son escasos los estudios sobre la socio-logía de este tipo de áreas residenciales suburbanas. Eso hace que con frecuencia se hagan generalizaciones que no acaban de estar respaldadas por evidencias contrastadas. Por ejemplo, desde la geografía y el urbanismo suele asumirse que las urbanizaciones dispersas son mundos homogéneos carentes de diversidad social ${ }^{4}$. Pero ¿de qué tipo de homogeneidad se trata? ¿Hay margen para la diversidad? Si existe esta diversidad, ¿de qué tipo es? Y si existe homogeneidad, ¿es ésta lo que motiva la elección residencial o es un efecto secundario de la misma? De igual manera, está ampliamente extendida la idea de que el suburbanismo obedece a tendencias antiurbanas, pero ¿hay en la motivación por irse a vivir a estos lugares un rechazo de la ciudad y a lo que ella representa? Y en todo caso, ¿cuáles serían los aspectos de la vida urbana de los que se huye? ¿La diversidad y la mezcla social? ¿La asunción del riesgo y la imprevisibilidad? ¿El anonimato y el encuentro cotidiano con el desconocido? ¿El ruido, la contaminación y el gris del cemento?

Con la intención de responder a estas preguntas, lo que voy a presentar aquí es el resultado de un estudio de caso conducido en 2009 sobre las urbanizaciones de Argentona, en la provincia de Barcelona. Pero antes de comenzar a desarrollar los

4 Un ejemplo de la reiteración de este tipo de supuestos se encuentra en varios de los colaboradores del monográfico de Indovina (2007) sobre las urbanizaciones de baja densidad. 
resultados es necesario enmarcar las preguntas anteriores y que nortean este estudio dentro de la teoría sobre el suburbanismo.

El proceso de suburbanización ha sido fuertemente cuestionado por parte de una larga tradición de urbanistas críticos Whyte, [1956] 2002; Mumdford, [1961] 2002;

Jacobs, [1961] 1973; Sennet, [1970] 2001; Mckenzie, 1995; Caldeira, 2000; Maurin, 2004). La crítica ha definido la suburbanización como un movimiento antiurbano por lo que significa de huida de lo que la ciudad compacta representa en cuanto al encuentro cotidiano con el diferente y la experiencia de afrontar lo imprevisible y asumir cierta dosis de riesgo. La migración a los suburbios habría estado en gran parte propulsada por el deseo de escapar de la mezcla de clases y grupos étnicos en las áreas urbanas. Se ha definido el ideal suburbano como la búsqueda de la comunidad homogénea desde el punto de vista racial, de clase social o de estilos de vida. Sin embargo, el suburbio americano, que se expandió como una oferta de vivienda para clases medias blancas, con el tiempo se fue "democratizando" (Bellet, 2007), atrayendo, incluso en las propuestas más radicales de tipo privativo (condominios, gated commnuties, etc.), un rango cada vez más amplio de grupos sociales. Con todo, el creciente acceso de minorías étnicas a los suburbios no ha evitado la reproducción de la segregación racial a nivel de diferentes suburbios, unos negros, otros blancos (Massey y Denton, 1992). Posteriormente, el movimiento de la New Suburban History (Kruse y Sugrue, 2006, Wise, 2006, Jones-Correa, 2006) criticó este relato por demasiado simple, ya que dejaba de lado la presencia de suburbios heterogéneos, donde clases medias cohabitan con residentes de clases trabajadoras y minorías étnicas. También se ha cuestionado la rigidez de la crítica tradicional del suburbio a la hora de pensar la comunidad, señalando que la homogeneidad social del espacio residencial no necesariamente implica redes y prácticas comunitarias homogéneas, ya que el espacio residencial solo es uno de los posibles espacios donde se construyen relaciones sociales, y dado el avance de la movilidad y de las tecnologías de comunicación, tal vez esté perdiendo relevancia (Nicolaides, 2006; Charmes, 2007).

Más que la búsqueda de una comunidad homogénea, como críticamente apuntaban Whyte ([1956] 2002) o Jacobs ([1961] 1973), y más recientemente retomaba Mckenzie (1995) con la noción de "privatopia", algunos autores (Miller, 1995; Charmes, 2007) han apuntado que la estructura espacial del suburbio promueve el aislamiento familiar debido a la falta de incentivos para socializar con los vecinos: la falta de espacio público (aceras, plazas, bares, comercios, etc), el predominio del vehículo privado para prácticamente toda movilidad, así como el disfrute de espaciosas casas con jardín que ofrecen todo tipo de entretenimientos para los residentes y demandan todo el tiempo del mundo para su mantenimiento. Esta inclinación hacia lo que Laura Miller (1995) llama "familiy togetherness", más que apuntar a una involución comunitarista antiurbana, representaría un paso más en el proceso de individualización que ya Louis Wirth ([1938] 1973) tipificaba como "modo de vida urbano".

\section{Estudio de caso: las urbanizaciones de Argentona}

En Cataluña, el tipo de urbanización dispersa de casas aisladas con jardín se ubica preferentemente en municipios pequeños, mientras que en los mayores las extensiones urbanísticas de baja densidad se producen en la modalidad de casas adosadas (Muñoz, 2007). En el caso de la comarcas costeras, las urbanizaciones de chalés 
están emplazadas en los municipios de interior, como ocurre en el caso de Argentona en la comarca del Maresme.

Las urbanizaciones de les Ginesteres, Can Raimí y Can Cabot, en el municipio de Argentona, fueron creadas en los años 70 por promotores privados que, con la aquiescencia municipal, vendieron las parcelas sin estar totalmente urbanizadas. Con una finalidad especulativa, los promotores urbanizaron fincas rústicas fuera de cualquier planeamiento urbanístico. Esta anomalía todavía se arrastra hoy en día de forma agravada. Lo que al principio era un lugar para casas de segunda residencia (torres), muchas autoconstruidas por trabajadores manuales originarios del sur de España, se fueron convirtiendo, a partir de los 90, en zona de primera residencia donde se instalaban familias de clase media procedentes de Mataró y del Área Metropolitana de Barcelona.

La falta de planificación y regulación de la urbanización se evidencia en la diversidad edificatoria: algunas casas están abiertas a la calle, plenamente visibles desde fuera, mientras otras viven literalmente de espaldas a la calle, ofreciendo al exterior la visión de un muro sin ningún elemento decorativo. Algunas casas son grandes y lujosas, otras son pequeñas y modestas. Casas de techos nórdicos conviven junto a cortijos andaluces y fachadas de inspiración palladiana. Todos los estilos, todos los tamaños, todos los colores y todas las formas se pueden encontrar en unas urbanizaciones que no han seguido una planificación ni una ordenación urbanística. Estamos por tanto muy lejos de las estampas cinematográficas del suburbio americano, del paisaje uniforme que tanto disgustaba a Lewis Munford (1961: 486), y aún más de promociones privativas tipo condominio (common interest housing) donde las normas de la comunidad especifican desde los elementos constructivos y decorativos hasta las normas de convivencia pasando por el tipo de propietarios permitidos (Mckenzie, 1995).

En las tres urbanizaciones mencionadas, las empresas promotoras quebraron y se dejaron sin completar los planes de urbanización, de manera que se quedaron sin red de alcantarillado ni conducción de gas. Las promotoras solo dotaron a las urbanizaciones de pavimento, red eléctrica aérea y canalización de agua. De las tres, únicamente la urbanización de Les Ginesteres está actualmente "recepcionada" por el Ayuntamiento después de que los parcelistas completaran la urbanización en el año 2000. A día de hoy, las urbanizaciones de Can Raimi y Can Cabot se encuentran en proceso de consolidar los proyectos por medio de Juntas de Compensación, y los propietarios-parcelistas deben hacerse cargo de las obras de urbanización pendientes. Pero la falta de acuerdo entre los residentes dificulta sacar adelante los proyectos necesarios para el recepcionamiento por parte de la administración municipal.

Las urbanizaciones no recepcionadas permanecen sin red de alcantarillado; la mayoría de residentes usa fosas sépticas, y parte de las aguas residuales se filtran al subsuelo. Es la Junta de compensación la que se ocupa del mantenimiento y salubridad del agua así como de poner remedio a los frecuentes problemas de recepción. Al mismo tiempo, la red eléctrica aérea provoca numerosos incidentes, ya que se trata de un terreno boscoso. Asimismo, el estado del alumbrado y la pavimentación es precario. Hasta el 2009, las urbanizaciones no disponían de servicio de transporte público, a excepción del escolar que funcionó durante un tiempo hasta que el ayuntamiento lo dejó de prestar alegando problemas de financiación. Las tres urbanizaciones carecen de equipamientos colectivos y apenas disponen de locales donde realizar reuniones de vecinos o actividades sociales.

En 2009, la población de las urbanizaciones de Argentona alcanzaba las 1531 personas (13\% del municipio). Los residentes de les urbanizaciones son una pobla- 
ción joven, destacando los cohortes de entre 25 y 44 años y de 0 a 14 años, lo que indica que en su mayoría están compuestas por un núcleos familiares con hijos.

Cuadro 1. Población por grupos de edad (\%)

\begin{tabular}{|l|c|c|c|c|c|}
\hline & $0-14$ & $15-24$ & $25-44$ & $45-64$ & $>65$ \\
\hline Urbanizaciones & $\mathbf{1 8 , 1 \%}$ & $10,9 \%$ & $\mathbf{3 7 , 1 \%}$ & $24,3 \%$ & $9,6 \%$ \\
\hline Argentona & $17,1 \%$ & $11,7 \%$ & $33,3 \%$ & $24,2 \%$ & $13,7 \%$ \\
\hline Cataluña & $15,9 \%$ & $9,3 \%$ & $21,3 \%$ & $26,4 \%$ & $27,1 \%$ \\
\hline Fuente: Elaboración propia a partir de actualización del Padrón de Argentona 2009 \\
\hline
\end{tabular}

A pesar de ser una población más joven que la del centro de Argentona, la proporción de personas con estudios superiores en las urbanizaciones es ligeramente inferior, aunque similar al del resto de Cataluña. En cambio, hay una mayor presencia de población ocupada perteneciente a la categoría profesional superior ("trabajadores no manuales de alta cualificación tales como directivos, profesionales y técnicos"): $54 \%$ en las urbanizaciones frente al $34 \%$ en Cataluña. Es decir, en las urbanizaciones predomina un tipo de población con más capital económico que cultural, formada principalmente por autónomos y pequeños empresarios con formación de grado medio.

Respecto al mercado de la vivienda, entre 1981 y 2011 las primeras residencias de Argentona pasan del 56\% al 75\% del parque de viviendas. Una transformación que no se debe únicamente a las urbanizaciones, aunque éstas han contribuido decisivamente. Según las inmobiliarias consultadas, la zona más cara de las urbanizaciones se localiza en Les Ginesteres, por ser la única urbanización que está recepcionada por el Ayuntamiento. En las urbanizaciones de Can Cabot y Can Raimí, actualmente, no se dan nuevas licencias de obras y eso dificulta la venta de viviendas ante la imposibilidad de poder hacer ampliaciones u obras de mantenimiento en casas que, en su mayoría, fueron construidas y mantenidas como segundas residencias.

\section{Trabajo de campo}

El trabajo de campo se realizó de marzo a diciembre de 2009. El trabajo que se presenta aquí es una pieza separada de un trabajo más amplio sobre compradores de vivienda en diversos tipos de hábitats urbanos (urbanizaciones de baja densidad, barrios gentrificados y barrios obreros periféricos). Por lo que respecta a las urbanizaciones de Argentona, se realizaron 17 entrevistas en profundidad a compradores recientes ${ }^{5}$. Además, se realizaron cinco entrevistas con agentes de intermediación inmobiliaria de la zona (dos de Argentona y tres de Mataró), así como tres entrevistas con técnicos municipales del Ayuntamiento de Argentona (urbanismo y guardia urbana). En el transcurso del trabajo de campo se mantuvieron numerosas conversaciones informales con diversas personas tanto de las urbanizaciones como de los

5 Inicialmente, el criterio de selección de personas a entrevistar era que hubiesen comprado en los últimos cinco años, pero se tuvo que ampliar a diez años ante la dificultad de conseguir entrevistas con este perfil tan acotado en un entorno donde, como veremos más adelante, la desconfianza inicial ante el desconocido es grande. 
núcleos urbanos de Argentona y Mataró que ofrecieron información adicional sobre la historia de las urbanizaciones así como sobre su imagen exterior. Por último, se analizaron fuentes secundarias, como el padrón y el censo de viviendas, publicidad inmobiliaria, revistas locales, etc.

El grueso de la información que vamos a proporcionar aquí procede de las entrevistas realizadas con residentes en las urbanizaciones que habían comprado su vivienda en los últimos diez años. Se trata por tanto de los pobladores recientes, un perfil que no incluye a los residentes antiguos que, habiendo comprado la parcela o la casa como segunda residencia, se quedaron a vivir de manera habitual.

Como vemos en el siguiente cuadro, entre los entrevistados predominan los pequeños empresarios y autónomos con estudios técnicos o de administración de empresas. La media de edad de los entrevistados es de 38 años y su trayectoria residencial indica que se emanciparon cuando tenían 25 años de media, coincidiendo con la cohabitación en pareja, y pasaron 2 años de media entre la emancipación residencial y la primera compra. Pero la media esconde situaciones muy dispares. Algunos siguen una pauta tradicional entre jóvenes de clase obrera que compran antes de vivir en pareja o que incluso viven un tiempo en pareja en la casa de algún progenitor después de haber comprado (Aramburu, 2015). Otros están largas temporadas de alquiler antes de comprar. En cualquier caso, la compra de casas unifamiliares en las urbanizaciones es posible gracias a la posesión de activos inmobiliarios previos. Para la mayoría de personas entrevistadas, la casa de la urbanización es una segunda o tercera vivienda en propiedad, a la que acceden en algunos casos sin tener totalmente pagada la anterior. Aun así, el esfuerzo económico para comprar estas casas es elevado ya que el pago de la hipoteca supone el $40 \%$ de los ingresos familiares.

Cuadro 2. Perfil sociodemográfico de las personas entrevistadas

\begin{tabular}{|c|c|c|c|}
\hline Número entrevistas & 17 & Edad de emancipación & 25 años \\
\hline Sexo & 9 mujeres, 8 hombres & $\begin{array}{l}\text { Edad de la primera } \\
\text { cohabitación en pareja }\end{array}$ & 25 años \\
\hline Edad media & 38 & $\begin{array}{l}\text { Edad de la primera } \\
\text { compra }\end{array}$ & 27,5 años \\
\hline Nacionalidad & $\begin{array}{l}16 \text { españoles } \\
1 \text { extranjero }\end{array}$ & $\begin{array}{l}\text { Primera o segunda } \\
\text { vivienda en propiedad }\end{array}$ & $\begin{array}{c}13 \text { segunda compra } \\
3 \text { primera compra } \\
1 \text { tercera compra }\end{array}$ \\
\hline Grupo doméstico & $\begin{array}{l}15 \text { pareja con hijos } \\
1 \text { pareja sin hijos } \\
1 \text { con dos núcleos } \\
\text { familiares } \\
\end{array}$ & $\begin{array}{l}\text { Precio de adquisición } \\
\text { de la vivienda actual }\end{array}$ & $\begin{array}{c}(2004) \\
332 \mathrm{mil} € \\
(120 \mathrm{mil}-600 \mathrm{mil})\end{array}$ \\
\hline Formación & $\begin{array}{c}7 \text { estudios superiores } \\
9 \text { estudios medios } \\
1 \text { estudios primer grado }\end{array}$ & $\begin{array}{l}\text { Cuota mensual } \\
\text { hipoteca }\end{array}$ & $\begin{array}{c}1232 € \\
(600 €-2.800 €)\end{array}$ \\
\hline Profesión & $\begin{array}{c}\text { Empresarios } \\
\text { Autónomos/as } \\
\text { Administrativas }\end{array}$ & $\begin{array}{l}\text { Esfuerzo económico } \\
\text { (relación entre la } \\
\text { cuota hipotecaria y los } \\
\text { ingresos familiares) }\end{array}$ & $\begin{array}{c}\text { Compra antes } 2004 \\
35 \% \\
\text { Compra a partir de } 2004 \\
45 \%\end{array}$ \\
\hline $\begin{array}{l}\text { Ingresos familiares } \\
\text { mensuales }\end{array}$ & 3300 euros & $\begin{array}{l}M^{2} \text { vivienda } \\
\text { construidos }\end{array}$ & $\begin{array}{c}163 \mathrm{~m}^{2} \\
\left(80 \mathrm{~m}^{2}-300 \mathrm{~m}^{2}\right)\end{array}$ \\
\hline
\end{tabular}




\section{4. ¿Huir de la Ciudad? Factores de atracción}

A excepción de dos personas que previamente habían vivido en urbanizaciones de baja densidad, el resto de entrevistados residía anteriormente en edificios plurifamiliares en núcleos urbanos densos. La descripción del proceso de búsqueda de vivienda que les condujo a la casa aislada de la urbanización es bastante similar en la mayoría de los casos. Comienzan el proceso de búsqueda dentro del propio núcleo urbano donde ya residían, movidos por la necesidad de mejorar las condiciones de vivienda, normalmente empujados por la necesidad de más espacio debido al crecimiento familiar. Tal como describen el proceso de búsqueda, descubren accidentalmente que por el mismo precio que les cuesta el piso que están buscando en la ciudad compacta pueden comprarse una casa unifamiliar en una de estas urbanizaciones.

Quim $^{6}$ (35 años): Vivíamos en un barrio de Mataró... en un quinto piso sin ascensor. Muy chulo, porque era un piso todo reformado pero... Llegó un momento que, por motivos personales, ya podíamos pues tener un cierto nivel adquisitivo más alto y entonces decidimos que, claro, el piso de allá ya había cumplido su función, y ya era cuestión de subir (pujar) a algo más, ¿sabes? Ya teníamos la elección de comprar algún piso más... Con ascensor y más comodidades (...) Pues... mirábamos en aquel momento de comprar un piso mayor con ascensor en Premià de Mar, ya que tenemos la empresa allá... Pero vimos que los precios eran muy excesivos, abusivos incluso, porque era justo en el boom inmobiliario (...) Vimos que era abusivo y comenzamos a mirar urbanizaciones... comenzamos a mirar y la casa más asequible que encontramos por la zona... Vimos que lo que nos costaba un piso en Premià o uno bueno en la zona de Mataró era lo que nos costaba la casa en la que vivimos ahora, y dijimos, bueno nos lo tenemos que pensar. Tiene inconvenientes porque está lejos... Pero tenía cosas positivas: tienes mucho terreno, tienes una casa, y si queríamos tener niños, porque todavía no teníamos niños... ‘¡Niño! Anda, ¡vete pa bajo!'Y ya está y te olvidas que tienes niños.

En el caso de Quim, como en la mayoría de los casos analizados, la urbanización dispersa no es la primera opción de búsqueda. Lo que buscan es mejorar la vivienda en la ciudad (buscando más metros, ascensor, etc.) pero en ningún caso señalan que la prioridad sea irse de la ciudad. Los factores expulsores que se suelen asociar con la vida urbana (contaminación, mezcla social, inseguridad) no aparecen en el discurso. Dos personas entrevistadas proceden de barrios que se podrían considerar de alto porcentaje de inmigración extranjera, pero cuando se les pregunta por ello no parece que eso haya influido de manera destacable en su decisión de irse a vivir a una urbanización.

Muchos cuentan que ya casi habían decidido comprarse un piso en Mataró o en Barcelona cuando, de manera fortuita, casi por casualidad, se enteran de que por el mismo precio que les piden por el piso al que aspiran en su núcleo urbano, pueden comprarse una casa con jardín en una urbanización, o pueden comprarse una parcela y construirse una vivienda. Tal como aparece en los relatos, la casa unifamiliar con

$6 \quad$ El fragmento está traducido del original en catalán. 
jardín en un entorno natural, que hasta ese momento solo estaba en su mapa mental como un sueño inalcanzable, de repente, gracias a la escalada del precio de la vivienda en las ciudades, se hace posible.

Lea, de Barcelona, descubrió esta posibilidad a través de un anuncio publicitario, y se le encendió la luz. Habían comenzado su búsqueda por Barcelona, y cuando estaban a punto de comprar un piso en el Eixample, de forma fortuita vieron un anuncio en una revista donde se anunciaba una casa en Argentona.

Lea $^{7}$ (34 años): [en Barcelona] al lado de nuestra casa había un piso que estaba bien, tenía 115 metros cuadrados y pedían 25 [millones de pesetas]. Entonces, íbamos a mirar ese, que si nos hubiese gustado seguramente nos lo hubiéramos quedado, pero... justo aquella misma noche... o sea, la noche anterior, eran las 12 de la noche, vimos un anuncio que ponía: 'casa de 200 y pico metros cuadrados, con mil metros de jardín, vistas al mar...' Ponía 20 millones de pelas. Dije: ¿¿dónde está eso? (...) Fuimos allá y alucinamos, solo de... solo de ver las vistas impresionantes. No tenemos ninguna casa delante que nos tape la vista. y nos emocionamos, ya no pensamos que estaba a 25 kilómetros de Barcelona [donde trabajan]. Nada, ya no pensamos absolutamente en nada. Fue ver aquel precio y aquella casa y con eso fue suficiente. Y sí, sí, aquel mismo día la cogimos.

Como ya señalara Pierre Bourdieu (2002) sobre la expansión de la vivienda unifamiliar en Francia, el flechazo de la casa con jardín impide pensar en otras cosas, como la lejanía, la falta de equipamientos del entorno o, como en el caso de Lea, la falta de infraestructuras básicas, como el alcantarillado, de cuya ausencia solo se percató una vez hubo comprado la vivienda. La casa con jardín emplazada en un entorno boscoso ("en la naturaleza") es un elemento de atracción citado por todas las personas entrevistadas. Este mito urbanita por antonomasia es en cierta manera también antiurbano, pero no tanto porque se plantee como la negación de una vida urbana que se juzga insoportable (es más bien una especie de fantasía o ensoñación que de pronto se hace realizable), sino porque el estilo de vida que promete (la amplitud del espacio privado disponible, el silencio ambiental, etc.) es imposible de llevar a cabo en la ciudad.

Asimismo, en la experiencia relatada en las entrevistas, el entorno social no es un valor que se tenga demasiado en cuenta a la hora de elegir comprar una casa en una urbanización; es la casa con jardín lo que importa. La localización, el hecho de que la casa esté aquí o allá, es secundario siempre que la distancia al trabajo no sea excesiva. A diferencia de lo que Savage et al (2002) llamaban elective belongers, en referencia a profesionales de la región de Manchester que sin tener vínculos previos con los emplazamientos rurales que eligen para vivir, desarrollan un fuerte vínculo de pertenencia a ellos (véase también Pujadas 2001 sobre la suburbanización de los profesionales lisboetas en la región saloia), no parece que los compradores en las urbanizaciones de Argentona desarrollen con el tiempo un apego al lugar. La sensación que trasmiten nuestros entrevistados es que podrían vivir en cualquier urbanización. Las urbanizaciones aparecen como lugares intercambiables, siempre y cuando sean más o menos accesibles respecto a sus lugares de trabajo. A la ausencia de sentido de pertenencia local en las urbanizaciones se refiere

El fragmento está traducido del original en catalán. 
Muñoz (2007: 65) con el concepto de "urbanalización”: “un tipo de urbanización independiente del lugar y, por tanto, replicable en cualquier espacio de manera que la forma urbana deja de representar así contenido cultural o simbólico alguno para la colectividad que supuestamente se tendría que sentir identificada y reconocida en aquel paisaje". En parecido sentido, se expresa Kauko (2007) sobre los suburbanitas de Rotterdam, cuyas preferencias se ven movidas por el interés instrumental antes que por el simbólico. Pero a mi modo de ver, no se trata tanto de que la urbanización deje de expresar contenido cultural o simbólico (tal cosa sería imposible), sino que la identificación con el lugar, siendo conceptual además de instrumental, está más vinculada a una determinada idea de estilo de vida que a la identificación con la historia y la identidad de un lugar concreto. En este sentido de falta de un significado histórico, podría decirse que la urbanización es un "no lugar" (Augé, 1993).

Asimismo, la identificación con la ciudad de Argentona es prácticamente nula. Se podría decir que el centro de Argentona y las urbanizaciones viven de espaldas. Los residentes en las urbanizaciones tienen un sentimiento de abandono por parte de la administración municipal que consideran injusto porque pagan "más impuestos" sin que eso se traduzca en una política municipal de mejora de sus condiciones de vida. Los residentes apenas van al centro de la ciudad, ya que la casa es el principal locus de sociabilidad, y las actividades lúdicas y de consumo no se suelen hacer en el municipio. La vinculación social con Argentona es mayor en aquellos casos en que los hijos van a escuelas públicas del pueblo, pero en no pocos casos se continúa llevando los hijos a las escuelas de la ciudad de procedencia, donde trabajan los padres o viven los abuelos.

\section{La casa con jardín como proyecto familiar}

Desprovista de un sentido de pertenencia local, la opción de comprar una casa con jardín se contempla como un elemento que rubrica una trayectoria social ascendente (housing ledder), que exterioriza una mejora de la posición social. Además, como la adquisición de la casa unifamiliar se hace a un coste económico elevado, las mejoras en el jardín o los acabados dentro de la propia casa generalmente son realizados por los propietarios.

Estos elementos de autoconstrucción generan la posibilidad de hacer una casa bastante personalizada y de diferenciarse de otros vecinos. La autoconstrucción ofrece dentro del marco suburbano una forma de diferenciarse y de recrear la propia identidad, al igual que Holston (1991) notaba en las periferias obreras de São Paulo. Pero, sobre todo, la vida en la urbanización está asociada a lo que Miller (1995) denomina family togetherness, un espacio vivido como un refugio familiar, un mundo doméstico autocontenido donde el marido, la mujer y los hijos hacen del hogar, la casa con jardín, el centro no solo de la vida familiar sino de toda la vida social, ya que incluso los fines de semana y las vacaciones se organizan en torno a este espacio.

Laura $^{8}$ (34 años): A mi me gusta más vivir en la urbanización... sea esta o sea la que sea, porque, tú puedes disfrutar de un espacio, no solo físicamente, el de la casa en sí, sino de un espacio verde. El solo hecho de salir allá fuera, ya es como si fueses a otro sitio, o sea no tenemos la necesidad de salir los fines de semana a pasarlos fuera

El fragmento está traducido del original en catalán. 
porque ya cuando sales a tu jardín o a la terraza ya estás disfrutando diferente... Sí que tiene muchos más gastos vivir en una urbanización, porque claro, no se puede comparar el agua de un piso con el agua de una parcela, más el gasto de luz... Los gastos se triplican. Los impuestos de una casa de allá no son los impuestos de un piso. Pero a nosotros nos resulta positivo: puedes dejar tu coche aparcado, si no es a un metro de aquí es tres metros más allá, y si tienes garaig pues todavía mejor. Y para los niños es ideal, puedes tener un tobogán, un columpio... A mí me gusta porque te da mucho más juego, sobre todo por el exterior (...) allá desconectas y no tienes tanta necesidad de marchar de vacaciones, por esto, ¿no?

La vida en la urbanización implica una devoción por la vida privada. Nociones como "tener espacio", "tranquilidad" y "desconectar" son las más empleadas para definir lo que más se valora de vivir en una urbanización. El aislamiento que, en una primera lectura, podría verse como algo negativo, se convierte para los residentes en una cualidad exclusiva de la vida en les urbanizaciones.

Los déficits urbanísticos con que se encuentran no son suficientes para renunciar a su nuevo proyecto de vida, contemplado como un "cambio radical", donde prima "la tranquilidad" del terreno ajardinado en medio de "la naturaleza" y las posibilidades de realización personal que les brinda "la casa", un proyecto en eterno devenir.

La vida social se realiza básicamente dentro de los límites de la propia casa, que no es tan solo un espacio donde residir. Hay un esfuerzo constante por parte de los miembros de la familia por crear un entorno donde pasar los fines de semana y las vacaciones, dedicando su tiempo libre a mejorar las prestaciones de la vivienda. Un tema recurrente son los planes y sueños de realizar nuevas obras de ampliación y remodelación, arreglar el jardín o crear zonas de juegos para sus hijos.

Al mismo tiempo, el amplio espacio disponible les permite desarrollar sus aficiones de manera personalizada: uno se dedica a la jardinería, otro pone un huerto, otro instala aparatos de gimnasia o canastas de básquet o monta un taller de herramientas; todo sin salir de casa. Como señala Laura, "sales al jardín y ya estás disfrutando de manera diferente". La amplitud del espacio permite una diversidad de experiencias, ofreciendo múltiples posibilidades de desarrollo personal: la jardinería, la horticultura, el deporte, el bricolaje. En contraposición, en la urbanización apenas hay equipamientos colectivos, y los que existen están bastante abandonados ${ }^{9}$.

La dedicación al proyecto familiar suburbano implica en ocasiones que un miembro de la pareja, normalmente la mujer, tenga que dedicar más tiempo a las tareas reproductivas (Martuccelli, 2006; Karsten, 2007). Entre las personas entrevistadas, en cuatro casos las mujeres habían abandonado el trabajo o reducido la jornada laboral para la crianza de los hijos y ocuparse de la movilidad (llevar y traer a los hijos de la escuela, al médico, ir a comprar, hacer gestiones, etc.), si bien estas renuncias no se presentaban como un sacrificio.

Se da la paradoja que en los años 70, cuando surgieron las urbanizaciones como zona de segundas residencias, había zonas recreativas, como piscina, frontón y campos de fútbol, así como una vida colectiva relativamente intensa que se expresaba en fiestas de verano y otras actividades. Sin embargo, con el tiempo, las zonas comunitarias se fueron abandonando, también como consecuencia de los elevados costos para mantenerlas de acuerdo con las nuevas normativas. A partir de los años 90, aunque las urbanizaciones comienzan a ser viviendas principales, la vida social y colectiva perdió intensidad. 


\section{Los trabajos y los días}

Es difícil saber dónde empieza la preferencia por el enclaustramiento familiar y dónde acaba la necesidad de tener que dedicar la mayor parte del tiempo libre disponible al trabajo de la casa. Ante el esfuerzo económico que representa el pago de la hipoteca ( $40 \%$ de media) las obras necesarias para mantenimiento y mejora de la vivienda les obliga a pasar vacaciones y fines de semana entregados a los trabajos de la casa. Las actividades de ocio fuera del espacio doméstico (cine, restaurantes, viajes, etc.) se restringen al máximo, y los ahorros deben destinarse a comprar materiales para mejorar las instalaciones de la vivienda, como señala Mònica.

Mònica $^{10}$ (35 años): Sí, sí, estaba toda, toda, toda por reformar. Claro, tú cuando entras allá son cosas que no ves... o sea, miras el mobiliario, miras eso, pero... éramos novatillos [ríe] entonces, claro, con la ilusión no miras... las tuberías. No miras la electricidad. Las cosas que no se ven no las miras. La miras con la luz del día porque te dicen que se ve mejor la casa y después vienen las sorpresas... La hemos tenido que... digamos... reformar, así internamente, toda, toda (...) Y todavía no hemos acabado. Ahora queda la parte del jardín, pero hemos tardado siete años. Siete años hemos estado, por las tardes, cuando salíamos de trabajar, fines de semana sin dormir. En el verano, nos hemos pasado todo el verano. Nos ha costado lo nuestro. Todo el dinero iba allá, pero sobre todo eso... ni salir ni viajar, nada de nada (...) y hemos aprendido a alicatar, hemos aprendido a... a hacer todo. Ya sabemos hacer cualquier cosa, hemos hecho toda una casa, toda la fontanería, todo, todo. Y hemos tardado lo nuestro, pero nos hemos ahorrado un montón de dinero, sobre todo en lo que es mano de obra.

Quienes compran casas antiguas deben dedicar tiempo y recursos a la rehabilitación (instalaciones eléctricas, cañerías, etc.) y quienes hacen una casa de nueva planta, encargan la obra a un constructor, pero como el presupuesto no suele alcanzar para contratar todas las tareas necesarias, los acabados interiores y las obras menores suelen ser realizadas por los mismos propietarios. Por ejemplo, el constructor hace el baño pero ellos ponen las baldosas. Esto hace que deban invertir su propio tiempo libre en finalizar las obras.

Manuel (38): Me he tenido que acabar la casa yo... así he aprendido a hacer de todo e incluso, ahora que he aprendido, hago para los demás, cosas que no eran propias mías, de paleta, de pintura, de herrería, todas estas cosas... (...) De hacer las obras en casa yo, que se te acaba el presupuesto y te tienes que espabilar o tienes que coger el toro por los cuernos, pues te tiras al ruedo. Pues al final aprendes de paleta, aprendes de... de... de todo. Ya te digo, hasta para hacer puertas de hierro y hacer de lo que haga falta.

Suelen ser los hombres los que realizan estas actividades que, no obstante, suelen requerir también la colaboración de la familia ampliada: hermanos, suegros, cuña-

10 El fragmento está traducido del original en catalán. 
dos... La procedencia obrera de muchos de ellos, sobre todo si tienen experiencia en construcción, facilita la empresa.

De esta manera, muchas veces la casa acaba implicando al resto de la familia extensa que, generalmente, reside en núcleos urbanos. Julia explica que para desbrozar el terreno de su casa requería de la ayuda de su padre y un amigo durante los fines de semana. Antonio tuvo la ayuda de su hermano pequeño para finalizar los interiores de la casa, poner baldosas o acabar la carpintería. Por tanto, la casa unifamiliar en la urbanización dispersa es una unidad doméstica que en cierto modo se aísla, pero que al mismo tiempo refuerza los vínculos extradomésticos al continuar dependiendo de la ayuda del resto de la familia extensa o de la red de amigos.

\section{7. ¿Espacios de homogeneidad social?}

Como ya se indicó, la búsqueda de la homogeneidad social ha sido uno de los aspectos más destacados en la literatura sobre el suburbanismo. En nuestra muestra, el perfil preponderante es el de familias nucleares con hijos pequeños que provienen de ciudades y que buscan un cambio de estilo de vida. Se trata de una clase media más rica en capital económico que cultural, compuesta mayoritariamente por autónomos y pequeños empresarios. Este perfil de los entrevistados coincide grosso modo con el poblador de las urbanizaciones de Argentona según indican los datos estadísticos mostrados anteriormente. Sin embargo, la imagen externa que tienen las urbanizaciones es que estas están compuestas por gente procedente de entornos obreros de origen inmigrante.

En las entrevistas realizadas con responsables de pequeñas inmobiliarias de Argentona y de Mataró, las persones entrevistadas, oriundas de estas poblaciones, elaboran un perfil similar del comprador típico de casas unifamiliares en las urbanizaciones: proceden de "barriadas" de Mataró o de ciudades del Área Metropolitana como Badalona o Sant Adrià. Este cliente que busca vivienda en urbanizaciones contrasta, según los profesionales inmobiliarios, con la preferencia de los vecinos del centro de Argentona o Mataró ("la gente del pueblo de toda la vida"), que prefieren quedarse a vivir dentro del núcleo urbano, aunque eso suponga vivir en un piso más caro o más pequeño. En cambio, el perfil de comprador de las urbanizaciones tendría un nivel económico "más bajo", generalmente son "gente de fuera" que proviene de "barriadas". Las inmobiliarias hacen una caracterización clasista de la clientela que es al mismo tiempo una caracterización etnicista y geográfica: obreros castellanohablantes de origen inmigrante de las periferias urbanas versus la clase media catalana del centro de la ciudad. Esta misma dicotomía también está presente en la gente de Argentona con la que se ha hablado, quienes consideran que los oriundos del pueblo no irían nunca a vivir a las urbanizaciones. Puede afirmarse que esta caracterización sociológica de las urbanizaciones dispersas en contraposición a los núcleos urbanos de las ciudades pequeñas donde aquellas se asientan está bastante extendida por diversas poblaciones catalanas.

Desde dentro de las urbanizaciones, la realidad social parece y es representada por los habitantes de manera más heterogénea de lo que es vista desde fuera. Entre la muestra de personas entrevistadas, los orígenes geográficos y de clase así como la lengua materna parece ser bastante diversa. Puede afirmarse que la imagen externa del habitante arquetípico de las urbanizaciones se forjó en gran medida en el origen de las mismas durante los años 70 , cuando los parcelistas eran obreros manuales, en muchos 
casos relacionados con la construcción, que procedían de barrios periféricos de ciudades cercanas, que compraban el terreno y se construían ellos mismos la torre (el chalé) en su tiempo libre. Muchos de los parcelistas eran inmigrantes del sur de España, y daban así continuidad a sus orígenes rurales a través del terreno donde podían cultivar su propio huerto y disfrutar del aire libre (véase también Bourdieu, 2003). Este perfil social no obstante varía considerablemente a partir de los años 90, cuando las viviendas pasan de segunda a primera residencia, dando lugar a un perfil social más heterogéneo. Sin embargo, la idea que se tiene desde fuera sobre los habitantes de las urbanizaciones sigue estando ligada al perfil sociodemográfico de los primeros moradores.

Aunque los residentes entrevistados suelen enfatizar la diversidad social, algunos destacan también este componente social de origen inmigrante como un elemento negativo de la urbanización. Es el caso de Carles, dueño de una empresa de interiorismo en Barcelona, que se hizo construir una casa que él mismo diseñó en un terreno que había heredado de su padre.

Carles $^{11}$ (45): La verdad que me arrepiento de haberme ido a vivir allá. Porque no es... ni el tipo de gente que me gusta como vecinos, ni el tipo de construcción que hay alrededor, ni las infraestructuras... Al final, tengo una casa grande, bonita y... y con la inversión que he hecho, bueno, me he dejado llevar por... por la ilusión, más que por la razón (seny), y al final dices: 'bueno, esta casa aquí no la venderás ni a tiros ... [ríe] por lo que vale realmente. (...) [El vecindario] es muy mezclado. Hay gente mayor de Barcelona, gente mayor de Mataró de toda la vida y catalanes y tal... y una masa importante de... de inmigración, digamos... nacional, con un nivel cultural relativamente bajo, que han hecho dinero pues a base de... como todo el mundo: uno que tiene una empresa, uno que tiene un comercio y tal... y al final han tenido algo, pero que social, que culturalmente tienen un nivel muy limitado, y entonces eso ocasiona que todo lo que son juntas y todo lo que son movidas de estas sean caóticas... Es que hay un caos (merder) allá dentro que es demasiado.

Si a Carles, el informante con mayor poder adquisitivo de la muestra, la diversidad social le resulta incómoda (no solo como parte del paisaje, sino porque tiene que lidiar con ella en las juntas de la asociación de propietarios, lo que a su juicio dificulta llegar a acuerdos), la diferencia social también puede ser perturbadora para aquellos que se incorporan a las urbanizaciones desde entornos sociales más populares, como Antonio, que procede de un barrio periférico y estigmatizado de Mataró, para quien las diferencias interclasistas en la urbanización, con sus divergentes hábitos de sociabilidad, resultan difíciles de sobrellevar.

Antonio (39 años): Yo se lo digo a mi mujer: 'Yo he aprendido a hablar con los perros, porque no tengo otra gente'. Yo me bajo abajo a ver los perros, yo les doy de comer, me pongo a hacer algo y hablo con ellos. Yo ya me he hecho amigo de ellos. Y... eso parece que no, pero se paga caro. Yo hubo un tiempo que estaba amargao, ¿eh? Porque decía: 'Me voy a apuntar a cualquier cursillo...' Llevaba como un mes inquieto, que decía que no me estaba gustando. Mi mujer me dice: 'Ah, eso son manías tuyas'. Digo: 'Manías ni leches. Voy a coger una depresión yo

11 El fragmento está traducido del original en catalán 
aquí'. Ahora ya porque me he acostumbrado y porque me hace ilusión hacer cosas, pero, si te quitan de aquí [del barrio de Mataró donde residía anteriormente], de tener la gente y tenerlo to, a irte a un sitio solo, a lo primero es muy bonito, esto es tranquilidad, esto... ¡Esto! ¡Una Leche! Esto, estás más solo que la una. Hubo un tiempo que estaba mu alterao. Que no, no me gustaba. Ahora me he hecho a la idea. Ahora estoy otra vez bien. Ahora, yo que sé, cuando llegue el invierno y empiece otra vez a... comerme el coco, pues me apunto a cualquier cursillo, yo que sé, a doblar camisetas, un cursillo de ahí por ponerte algo. (...) Aquello es muy frío, la relación con los vecinos es frío. Joer, lo que te diga yo. Tú en tu casa y yo en la mía. (...) Aquellos que tengo enfrente, ehh... La hija es abogada, es muy simpática, ¿eh? Te ve: ‘Hola, ¿Qué tal?’ Y esto y lo otro. Pero... en su casa. Ehhh... los padres son gestores de... de una gestoría, muy pijos, muy... son muy educados: 'Hola, Buenos días. ¿Todo bien?' Pero... lo justo. El de abajo, no. El de abajo que tiene el negocio en Barcelona, ese es más campechano, ese me invitó un día a cerveza (...) me tuvo hasta la una de la noche allí en su casa. Ese es más campechano y... viene más a mi casa, pero con los demás, muy frío. Es más, si te acercas por su puerta parece que les molesta. Eso es lo que tienen las urbanizaciones, gente que... van mucho a su aire. Allí no te pienses que... que era como en el piso que yo ahora estaba aquí [en Mataró] y me decía: 'Me voy a ver al del $3^{\circ}$ un rato’ y me iba a su casa o bajaba él a mi casa. Eso, eso allí no existe. Eso... allí cada uno en su casa, (...) porque allí la mayoría son, son empresarios... son muy educados, ¿eh? O sea, yo creo que, tú vas por allí y son muy cordial: 'Buenos días, Buenas tardes'. Muy educados, pero que no...

Antonio, crecido en un barrio obrero, con unas formas más intensas de sociabilidad vecinal, no acaba de sentirse a gusto con un tipo de relación social basada en la distancia cordial. La vida de la urbanización marcada por los vínculos débiles le supone un esfuerzo de adaptación notable. Pero, en cualquier caso, los relatos cruzados de Carles y Antonio, con su recíproca incomodidad de clase, muestran que la urbanización está lejos de constituir un mundo socialmente homogéneo.

Aun así, el tipo de civilidad preponderante en las urbanizaciones se basa en que los vecinos respeten la intimidad de los otros, de quienes al mismo tiempo se espera respeto y cordialidad. Los lazos sociales fuertes se sitúan fuera de la urbanización y generalmente están vinculados a sus lugares de procedencia, donde habitualmente residen amigos íntimos y familiares más próximos. Pero al mismo tiempo, las condiciones de vida de la urbanización impiden que los residentes sean átomos sociales que van cada uno por su cuenta; se necesita cierta vinculación para mantener el control social necesario para una mínima sensación de seguridad.

\section{Relaciones débiles, control y previsibilidad}

A pesar de la tendencia general hacia la primacía de la vida privada, en las urbanizaciones los vínculos vecinales son absolutamente necesarios para mantener cierta atmosfera de seguridad y confianza. La urbanización no es lugar para el anonimato ni para el encuentro con el extraño ni para la experiencia de lo imprevisto. En este sentido sería lo contrario de un "no lugar" (Augé, 1993), sería más bien un lugar en que, "como en una aldea, es imposible observar sin ser observado" (Pujadas, 2001: 
130). A falta de "ojos [anónimos] que miren a la calle" que para Jane Jacobs ([1961] 1973: 38 y ss.) proporcionaban las bases securitarias de la vida urbana, en las urbanizaciones la sensación de seguridad, siempre amenazada, solo se puede restituir a través del control permanente de quién es quién, y esto requiere el conocimiento interpersonal y recíproco. Solo así se puede detectar rápidamente a los extraños, que son fuentes potenciales de agresión en un entorno de aislamiento.

El conocimiento recíproco entre vecinos en un entorno como las urbanizaciones, donde las familias se mantienen aisladas dentro de sus casas, es un factor importante para mantener una atmosfera de orden y previsibilidad. Conocer los vehículos que utilizan los vecinos más próximos proporciona una información relevante para detectar posibles incursiones de personas extrañas, que son percibidas con inquietud. Conocer los coches de los vecinos les permite estar más "tranquilos" al poder reconocer instantáneamente los posibles intrusos. A diferencia de lo que ocurre en las gated communities, donde se controla el acceso de los no residentes, en las urbanizaciones que nos ocupan el acceso de visitantes es libre, y eso levanta todo tipo de suspicacias. Se entiende que a la urbanización únicamente van los residentes y por tanto el resto de personas que accede debe ser sometido a una cierta observación desconfiada. La angustia ante la presencia de desconocidos la podemos ver en la siguiente anécdota que cuenta María. Un día, al regresar a casa de noche, se encontró frente a su domicilio un coche aparcado que no pertenecía a ningún vecino. Alarmada por este hecho fuera de lo habitual, inmediatamente avisó a la policía.

Maria $^{12}$ (36 años): Siempre miro los coches y hubo una vez que me acojoné. Y [la policía] tardaron 10 minutos. 10 minutos tardan, bueno si tienes suerte... A veces tardan más, pero sí que los pobres vienen, vienen cuando pueden. Tardaron $10 \mathrm{mi}-$ nutos, que había un coche que había un par de moros... Bueno, había tres, sí, que estaban fumando, y llegué a las 11 de la noche y justo delante de casa... ¿Sabes qué pasa?. La gente aparca al lado de casa, y si ves un coche que no conoces...... O sea, conoces todos los coches de todos, y aquel era un Smart.

En este clima securitario, el coche se convierte en una forma de identificación del vecindario. De hecho, aunque la mayoría de vecinos dispone de espacio dentro de su finca para aparcar los coches, se ha creado el hábito de dejar un coche aparcado en la calle frente a la casa. Se trata de una forma de comunicar que los propietarios están dentro de la vivienda, en un mensaje no solo dirigido a los intrusos sino también a los vecinos, que saben que si el coche no está aparcado frente a la casa deben alarmarse si perciben algún movimiento en su interior.

En cualquier caso, el aislamiento de la urbanización genera una sensación de inseguridad omnipresente que a su vez obliga a mantener los vínculos vecinales, aunque sean débiles. El control vecinal recíproco que deriva del miedo a la agresión impide que los vecinos se orienten totalmente hacia la vida privada y la preservación de la intimidad. Unos y otros dependen de estas vigilancias recíprocas para disuadir a los agresores potenciales y para proporcionarse a sí mismos cierta sensación de

12 El fragmento está traducido del original en catalán. 
protección mutua. Así pues, las relaciones vecinales, aunque sean débiles y distantes y no vayan más allá de un saludo cordial, son esenciales para mantener la seguridad y el orden de la vida en la urbanización.

Si desde Simmel (1973[1903]) y Weber (1973[1921]), la vida urbana se ha definido por el anonimato y la imprevisibilidad, las urbanizaciones de baja densidad son su contrario. La vida en la urbanización depende de mantener a los extraños bajo control, lo que implica en primer lugar tener identificados a los no-extraños.

Si la preocupación por la seguridad los une a través de un control recíproco que genera unos vínculos débiles, los conflictos en torno a la finalización de las obras de urbanización y el recepcionamiento de la urbanización por parte del ayuntamiento generan una elevada conflictividad, pero también formas de agregación en términos de facciones, es decir, de vínculos fuertes.

\section{Formas de agregación y disgregación en las urbanizaciones}

El proceso que lleva al recepcionamiento de la urbanización por parte del Ayuntamiento (es decir, el momento en que se hace cargo de los servicios urbanos esenciales) es un elemento político central en la vida de la urbanización y en gran parte determina la forma cómo se articulan las relaciones entre los vecinos.

Según explican los entrevistados de Can Cabot y Can Raimí, que además de no disponer de red de alcantarillado (y por tanto tener que recurrir a fosas sépticas) deben ocuparse del mantenimiento del asfaltado, la red eléctrica, las instalaciones de agua corriente, etc., cuando compraron su casa en la urbanización desconocían las carencias con las que se iban a enfrentar. Ni los vendedores ni los intermediarios les informaron que debían hacerse cargo del asfaltado de la calle, del mantenimiento de la red eléctrica o de la recogida de basuras. Aunque esta información está disponible en el Ayuntamiento de Argentona o en la propia escritura pública de las viviendas, ninguno de los compradores entrevistados admite haber preguntado por el tema cuando compró. Asimismo, desde el Ayuntamiento de Argentona, señalan que recibían pocas consultas sobre estas condiciones y, casi siempre, con posterioridad a la compra.

Llevar a cabo las obras de urbanización pendientes que son necesarias para el recepcionamiento, implica tener que organizarse, y supone, como también nota Indovina (2007: 21), la gran ironía de que personas que han ido a vivir allí movidos por un proyecto privatista de aislamiento familiar se ven obligados a dedicar un tiempo considerable a la organización de la urbanización, a cooperar con otros vecinos para organizar estos servicios y presionar colectivamente al ayuntamiento para que se haga cargo, lo que implica participar activamente en reuniones y consensuar una estrategia colectiva. Estas actividades organizativas conducen a enfrentamientos que acaban dividiendo a los vecinos de la urbanización en facciones enfrentadas.

Para que el ayuntamiento se haga cargo de la gestión de las infraestructuras en las urbanizaciones, los vecinos deben acometer una serie de obras de reurbanización y reparcelación. Esto obliga a los vecinos a coordinarse de manera regular y suele dividir el tejido social entre partidarios y detractores de afrontar las obras y por tanto de asumir el gasto que estas implican (que en algunos casos ascienden a $40.000 €)$. La controversia en torno al dinero que se debe destinar a finalizar las 
obras de la urbanización genera desconfianza entre los vecinos y da lugar a la creación de grupos enfrentados, como explica Juan, venezolano y único extranjero de la muestra.

Juan (37 años): Es que son bandos, más que bandos somos clanes, el clan de fulano, el clan de mengano, es así... Sociológicamente parecemos tribus, somos los de la tribu de fulano, y somos los de la tribu de mengano. También por el nombre, a uno le dicen Robin Hood, y al otro le dice, no sé... Y es una forma de, de pertenecer a un grupo y de ir a favor o en contra... Y yo es que no soy de ningún grupo. Yo soy el independiente (...) el que quiere hacer las obras y el que no quiere hacer las obras (...) creo que mucho del inmigrante que viene del sur, que le ha costado mucho sacrificio comprar su casa, que lo ha visto como su inversión, que ha llegado hasta aquí. Y... y que ha tenido que trabajar mucho y con... con un nivel, vamos a decir educativo medio-bajo, que es gente que ha venido a trabajar, de obrero... hacen un grupo. Después los... hay otro grupo que es un núcleo duro, que son los catalanes-catalanes y luego estamos los independientes, que no somos ni... que no somos ni del uno ni del otro, pero que tratamos de reunirnos aunque tengamos puntos de vista distintos.

Generalmente, son los nuevos residentes los que están más motivados para llevar a cabo las obras, mientras que los antiguos propietarios que compraron en los años 70 y 80 son los que tienen menos interés en acometer las obras. Muchas veces esta oposición viene ocasionada porque la mayoría de primeros propietarios ya son jubilados y no disponen de capital para hacer frente al importe de las obras. Por su parte, los nuevos propietarios, más jóvenes y económicamente activos, necesitan legalizar la situación para poder maximizar la propiedad como valor de cambio. La atmósfera de desconfianza que se expresa en las juntas de la asociación de propietarios expresa y refuerza a la vez divisorias sociales en términos étnicos y de clase: los viejos ocupantes de origen inmigrante y obrero frente a los nuevos residentes de clase media catalana.

El conflicto deviene un divisor social pero también un aglutinador social, en la medida que crea facciones compuestas por personas con intereses compartidos. Un indicador de que el conflicto produce no solo disgregación sino también dinámicas de agregación es que cuando aquél desaparece, se refuerza la dinámica de aislamiento familiar. Eso es lo que parece haber sucedido en Les Ginesteres, la única urbanización de la zona recepcionada por el Ayuntamiento. Aquí la administración local se hace cargo de las infraestructuras básicas necesarias, y eso hace que las compañías de servicios puedan instalar conducción de gas natural, red eléctrica y telefónica, etc. Los vecinos ya no tienen la necesidad de asociarse para encargarse de las tareas de mantenimiento de la urbanización. En conversaciones informales con personas que residen en la urbanización desde hace tiempo, algunos desde sus inicios, constatan que al desaparecer la problemática del recepcionamiento como eje vertebrador de la vida colectiva, los vecinos se desvincularon de la Asociación de propietarios y dejó de realizarse cualquier tipo de actividad conjunta. De hecho, actualmente la Asociación tiene un presidente pero no tiene junta activa ni se realiza ninguna reunión de vecinos. Todo indica que en Les Ginesteres, donde el Ayuntamiento se hace cargo del mantenimiento de los servicios urbanos, la vida 
colectiva es menos intensa que en las urbanizaciones que no están recepcionadas, como en Can Raimi y Can Cabot.

\section{Conclusiones}

El aspecto más notorio del suburbanismo catalán es la precariedad de las infraestructuras urbanas básicas de estas urbanizaciones semi-legalizadas. Esta situación se mantiene en muchos casos relativamente inalterada desde su origen, cuando albergaban segundas residencias autoconstruidas por familias obreras, situación que heredan las familias de clase media (algunas también de origen obrero) que a partir de los años 90 hacen de la urbanización su vivienda habitual.

Mucho se ha discutido sobre si el suburbanismo constituye una tendencia antiurbana. En el caso que analizamos aquí, las personas entrevistadas, cuando racionalizan la opción suburbana, no la presentan como una huida de la ciudad y sus supuestos males, ni rechazan propiamente la ciudad, entre otras cosas porque siguen haciendo un uso intensivo de la ciudad, donde trabajan, tienen la escuela de sus hijos o viven amigos y familiares. La instalación de familias de clase media en la urbanización dispersa ocurre en primer lugar por el efecto expulsor de los precios de la vivienda en los núcleos urbanos densos, y solo entonces se hace efectiva la atracción de la casa aislada con jardín. Sin embargo, el proceso es ambivalente pues la opción suburbana, sin ser conscientemente antiurbana, lleva a un tipo de experiencia que difícilmente puede considerarse urbana, ya que lo extraño y lo imprevisible no tienen cabida o están sujetos a una vigilancia que presenta una radicalidad sin parangón en la ciudad densa.

Otro aspecto crítico del suburbanismo es la homogeneidad social que se le presupone. En nuestro caso, más que un mundo socialmente homogéneo aparece una cierta heterogeneidad de fracciones de la clase media (también caracterizadas étnicamente) que en gran parte es resultado de la transición inacabada entre los primeros pobladores y los nuevos, que proceden de entornos sociales (parcialmente) diferentes, y cuya convivencia está sujeta a tensiones importantes. Con todo, los nuevos pobladores de la urbanización, más que buscar un entorno de homogeneidad social, parece que lo que persiguen en primer lugar es un aislamiento familiar en la casa con jardín, un mundo relativamente autocontenido que sirva a la vez de lugar de residencia y de esparcimiento donde pasar todo el tiempo libre posible, de lo que también resulta una cierta homogeneidad de estilos de vida y formas de sociabilidad preponderantes. No obstante, no está claro dónde empieza la devoción doméstica y dónde acaba la necesidad de dedicarse en cuerpo y alma a la inacabable tarea de conservar y mejorar la casa con jardín.

El proyecto privatista de estas urbanizaciones es un proyecto muy distinto de la utopía privatista de tipo comunitario (privatopia) estudiada entre otros por McKenzie (1995), donde el todo comunitario somete a las partes individuales y busca reproducir su autonomía política en la gestión del condominio. En nuestro caso el privatismo es de tipo familiar, totalmente orientado hacia el cultivo de la intimidad doméstica, y al mismo tiempo busca que la administración municipal asuma los servicios urbanos esenciales. Y sin embargo, la orientación comunitaria seguramente es más necesaria que en la ciudad densa. Por una parte, mantener vínculos vecinales (aunque débiles) es absolutamente necesario para contrarrestar la vulnerabilidad y la inseguridad sentidas en las urbanizaciones. Por otra parte, el 
proyecto de traspasar a la administración municipal la gestión de los servicios urbanos supone un proyecto de organización colectiva altamente exigente. Por tanto, la urbanización dispersa, lejos de constituir un texto transparente, es un mundo de numerosos contrastes y paradojas.

\section{Referencias bibliográficas}

Aramburu, Mikel (2015). "Rental as A Taste of Freedom: The Decline of Home Ownership amongst Working-class Youth in Spain during Times of Crisis". Journal of Urban and Regional Research. 39 (6): 1172-1190. DOI: 10.1111/1468-2427.12218

Augé, Marc (1993). Los no lugares. Espacios del anonimato. Barcelona: Guedisa.

Bellet, Carmen (2007). "Los espacios residenciales de tipo privativo y la construcción de la nueva ciudad: visiones de privatopia". Scripta Nova, 245.

Bourdieu, Pierre (2003). Las estructuras sociales de la economía. Barcelona: Anagrama.

Barba, Joan; Mercadé Montserrat (2007). "Diagnosis de las urbanizaciones residenciales en la provincia de Barcelona", en Francesco Indovina (Coord.) La ciudad de baja densidad. Lógicas, gestión, contención. Barcelona: Diputación de Barcelona, 85-96

Caldeira, Teresa (2000). Cidade de muros. Crime, segregação e cidadania em São Paulo. Editora da Universidade de São Paulo: São Paulo.

Charmes, Eric (2007). "Suburban fragmentation versus mobilities: is suburbanism opposed to urbanism?" Cybergeo: European Journal of Geography, 369. Disponible en http:// cybergeo.revues.org/4882 ; DOI: 10.4000/cybergeo.4882.

Davis, Mike (2006[1990]). City of quartz. Excavating the future in Los Angeles. New York: Verso.

Fava, Sylvia (1956). "Suburbanism as a way of life", American Sociological Review, 21: 34-37.

Holston, James (1991). “Autoconstruction in Working-Class Brazil”, Cultural Anthropology, 6: 447-465.

Indovina, Francesco (Coord.) (2007). La ciudad de baja densidad. Lógicas, gestión, contención. Barcelona: Diputación de Barcelona, 13-22.

Jacobs, Jane ([1961] 1973). Muerte y vida de las grandes ciudades. Barcelona: Península.

Jones-Correa, Michael (2006). "Reshaping the American Dream: Immigrants, Ethnic Minorities, and the Politics of the New Suburbs". En Kevin Kruse y Thomas Sugrue (Eds.) The New Suburban History. Chicago: The University of Chicago Press, 183204.

Karsten, Lia (2007). "Housing as a way of life: towards an understanding of middle-class families preference for an urban residential location", Housing Studies, 22 (1): 83-98.

Kauko, Tom (2006). "What makes a location attractive for the housing consumer? Preliminary findings from metropolitan Helsinki and Randstad Holland using the analytical hierarchy process", Journal of Housing and the Built Environment, 21 (2): 159-176. DOI: 10.1007/ s10901-006-9040-y

Kruse, Kevin; Sugrue, Thomas (Eds.) (2006). The New Suburban History. Chicago: The University of Chicago Press.

Levy, Deborah; Murphy, Lorence; Lee, Christina (2008). "Influences and Emotions: Exploring Family Decision-making Processes when Buying a House". Housing Studies, 23 (2): 271-289. DOI: 10.1080/02673030801893164.

Lupi, Tineke; Musterd, Sako (2006). "The suburban 'community question'”, Urban Studies, 43 (4): 801-817. DOI: 10.1080/00420980600597723 
Mairal, Gaspar (2000). "Una exploración etnográfica del espacio urbano", Revista de Antropología Social, 9: 177-191.

Márquez, Raúl (2015). "La propiedad como hecho social. Una contribución etnográfica a la crítica del economicismo", Revista de Antropología Social, 24: 83-104. DOI: 10.5209/ rev_RASO.2015.v24.50644

Martuccelli, Danillo (2006). Forgé par l'épreuve. L'individu dans la France contemporaine. París: Arman Colin.

Massey, Douglas, Denton, Nancy (1992). American Apartheid: Segregation and the Making of the Underclass. Cambridge: Harvard University Press.

Maurin, Eric (2004). Le ghetto français. Enquête sur le séparatisme social. París: Éditions du Seuil / La Republique des Idees.

Mckenzie, Evan (1995). Privatopia: Homeowner associations and the rise of the residential private government. New Haven: Yale University Press.

Miller, Laura (1995). "Family Togetherness and the Suburban Ideal" Sociological Forum,10 (3): $393-418$

Mumford, Lewis (1961). The City in History. Its origins, its transformations, and its prospects. New York: Harcourt, Brace and World.

Muñoz, Francesc (Coord.) (2011). Estratègies vers la ciutat de baixa densitat: de la contenció a la gestió. Barcelona: Diputación de Barcelona.

Muñoz, Francesc (2007). "La producción residencial de baja densidad en la provincia de Barcelona (1985-2001)", en Francesco Indovina (Coord.). La ciudad de baja densidad. Lógicas, gestión, contención. Barcelona: Diputación de Barcelona. 51-84.

Muxí, Zaida (Coord.) (2013). Postsuburbia. Rehabilitación de urbanizaciones residenciales monfuncionales de baja densidad. Barcelona: Comanegra,

Nicolaides, B. (2006). "How Hell moved from the city to the suburbs", en Kruse J. Sugruem, T. (Eds.). The New Suburban History, Chicago: The University of Chicago Press, 80-98.

Pujadas, Joan (2001). “A propósito de Lisboa: espacios urbanos, historia y memoria", Revista de Antropología Social, 10: 123-149. DOI: 10.5209/rev_RASO.2001.v10.10747

Savage, Michael; Bagnar, Gaynor; Longhurst, Brian (2002). Globalization and belonging. Nottingham: Sage Publications.

Sennet, Richard (2001[1970]) Vida urbana e identidad personal. Barcelona, Ediciones Península.

Simmel, George (1973[1903]). “A metrópole e a vida mental”. En Otavio Velho (comp.) O fenômeno urbano. Rio de Janeiro Zahar Editores, 11-25.

Síndic de greuges (2012). "Informe del Sindic de Greuges sobre les urbanitzacions amb déficits". Disponible en: http://www.sindic.cat/site/unitFiles/3451/Informe\%20urbanitzacions-CAT. pdf

Weber, Max (1973[1921]). “Conceito e Categorias da Cidade”, En Otavio Velho, (comp.). O fenômeno urbano. Rio de Janeiro: Zahar Editores, 68-89.

Whyte, William ([1956] 2002) The organization man. Philadelphia, University of Pensilvania Press.

Wirth, Louis ([19731938]). “O urbanismo como Modo de Vida”. En Otavio Velho. (coord) $O$ fenômeno urbano. Rio de Janeiro: Zahar Editores, 90-113.

Wise, A. (2006). "The House I live In. Race, Class, and African American Suburban Dreams in the Postwar States". En Kevin Kruse y Thomas Sugrue (Eds.). The New Suburban History, Chicago: The University of Chicago Press. 99-119. 